\title{
ANÁLISE DE PROJETOS DO MEIO AMBIENTE NO CONTEXTO ESCOLAR
}

\author{
Flávia Silva de Almeida ${ }^{1}$ \\ Diógenes José Gusmão Coutinho
}

RESUMO: No trabalho abordado foi realizado a análise de projetos que envolvem a questão do meio ambiente com o objetivo de obter o conhecimento científico e a melhoria do ensino aprendizagem no ambiente escolar, bem como a capacidade de torna-se um cidadão crítico nas escolhas previstas e no âmbito do protagonismo do aluno que se compromete com o trabalho em questão, principalmente em tempos de globalização é percebido a necessidade de qualidade no ensino aprendizagem no contexto escolar. O objetivo específico é planejar e executar os projetos interdisciplinares na escola; estimular os educandos na participação dos projetos elaborados para construção dos seus saberes: éticos, estéticos e políticos, e envolver os participantes dos projetos no desenvolvimento da própria criticidade sobre o assunto abordado. A partir do objetivo geral e específicos surge a justificativa do trabalho, pois algumas escolas planejam projetos interdisciplinares durante a construção do Projeto Político Pedagógico (PPP), por outro lado poucas escolas que constroem o planejamento no PPP não os executam. As problemáticas do trabalho desenvolvido são sobre "Como tem sido realizado os projetos do meio ambiente na escola?". "Qual a necessidade de ter conhecimento e mudança da postura dos professores em relação ao meio ambiente e ao desenvolvimento sustentável? Dentre as hipóteses que foram observadas são: Os conteúdos são prioridades no cotidiano dos docentes, não havendo um espaço de tempo para aplicação de projetos, além do calendário de provas, existe projetos e provas externas pré-existentes nas escolas públicas que tomam bastante tempo não possibilitando a prática do mesmo. A metodologia tem um itinerário de revisão sistematizado da literatura, na qual serviu de referências para buscas nos sites de teses e dissertações, bem como publicação em revistas, jornais, a fim de buscar alternativas de projetos eficazes ou não para o meio ambiente em meio ao contexto vivido. $\mathrm{O}$ presente trabalho se baseou nos seguintes autores: "O uso de projetos na escola tem como finalidade trazer a realidade para o âmago da sala de aula, com o objetivo da aprendizagem", (SANTANNA, 2014, p. 30), e BARBA (2016) afirma que o estudo sobre meio ambiente na escola é recente e pouco visto, uma vez que é considerado pelo autor como "déficit de natureza. Os projetos são um instrumento de grande valia no meio escolar.

Palavras- Chave: Projetos. Meio ambiente. Escola.

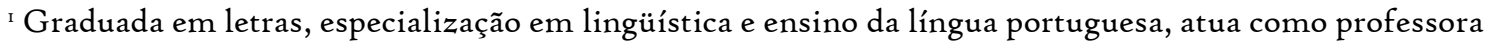
de língua portuguesa na prefeitura do Recife.

${ }^{2}$ Mestre e doutor em biologia pela UFPE- Universidade Federal de Pernambuco- Orientador do curso de mestrado e doutorado pela Alpha Faculdade e Centro Universitário Brasileiro - UNIBRA, Brasil, email: gusmao.diogenes@gmail.com.
} 
ABSTRACT: In the work discussed, the analysis of projects involving the issue of the environment was carried out in order to obtain scientific knowledge and improve teaching and learning in the school environment, as well as the ability to become a critical citizen in the planned choices and within the scope of the protagonism of the student who is committed to the work in question, especially in times of globalization, the need for quality in teaching and learning in the school context is perceived. The specific objective is to plan and execute the interdisciplinary projects in the school; encourage students to participate in projects designed to build their knowledge: ethical, aesthetic and political, and involve project participants in the development of their own criticality on the topic addressed. From the general and specific objective comes the justification for the work, as some schools plan interdisciplinary projects during the construction of the Pedagogical Political Project (PPP), on the other hand few schools that build the planning in the PPP do not execute them. The issues of the work developed are about "How have the projects for the environment at school been carried out?". "What is the need to have knowledge and change the attitude of teachers in relation to the environment and sustainable development? Among the hypotheses that were observed are: Contents are priorities in the daily lives of teachers, with no time frame for implementing projects, in addition to the exam calendar, there are projects and pre-existing external exams in public schools that do not take a lot of time. enabling the practice of it. The methodology has a systematic literature review itinerary, which served as references for searches on theses and dissertations on websites, as well as publication in magazines, newspapers, in order to seek alternative projects that are effective or not for the environment in the context vivid. The present work was based on the following authors: "The use of projects at school aims to bring reality to the heart of the classroom, with the objective of learning", (SANTANNA, 20I4, p. 30), and BARBA ( 2016) states that the study on the environment at school is recent and little seen, since it is considered by the author as a "deficit of nature. Projects are a very valuable instrument in the school environment.

Keywords: Projects. Environment. School.

\section{INTRODUÇÃO}

A pesquisa realizada tem ênfase na implementação de projetos que promovam mudança comportamental na vida dos jovens que estão na escola, trazendo um tema de alta relevância "Meio Ambiente", além de fazer parte do currículo, por diversas vezes se encontram-se no Projeto Político Pedagógico da Escola (PPP), mas do papel não saem. Geralmente estão nos escritos relatando: Semana do meio ambiente e a data. Se bem que os atores sociais, que tratam da educação com atenção devem conhecer o PPP da escola, mesmo sem ele ser oferecido pela gestão ou coordenação, pois as posturas devem ser mudadas para alcance da proposta de ensino aprendizagem. Consoante as orientações da Secretaria de Estado de Educação O Projeto Político- 
Pedagógico (PPP) é um instrumento teórico-metodológico para a intervenção e mudança da realidade. É um elemento de organização e integração da atividade prática da instituição neste processo de transformação (VASCONCELLOS, 2014, p.I69). Não obstante de ser consultado, uma vez que o mesmo é construído coletivamente. $\mathrm{O}$ conselho escolar pode fiscalizar se as metas pedagógicas estão sendo alcançadas.

A prática de projetos na escola aumenta o interesse, rendimento e proporciona um saber participativo e a Educação ambiental segundo Ross e Becker (2012) promove a metodologia em conjunto, no qual o indivíduo assume e adquire papel principal no processo de ensino aprendizagem, sendo que cada pessoa deve participar da análise de cada problema socioambiental encontrado. Os autores muito colaboram nas questões de projetos, durante as leituras de textos acadêmicos já publicados, assim enriquecendo a pesquisa proposta no intuito de análise dos projetos de meio ambiente na escola. As revisões sistemáticas de literatura são 'desenhadas' para serem metódicas, explícitas e passíveis de reprodução (MANCINI; SAMPAIO, 2007).

Os instrumentos utilizados para pesquisa são os possíveis projetos na construção do procedimento técnico da pesquisa explicativa, abordando o método qualitativo." O procedimento técnico para o avanço das ideias na visão de Yin (2010), aborda planejamento e interliga coleta e análise de dados, a estratégia acontece do meio externo para o meio interno.

\section{AS REFLEXÕES SOBRE MEIO AMBIENTE ATRAVÉS DA LEITURA}

A abordagem permite o desenvolvimento cognitivo do aluno com a interação dos livros, alunos, professores, literatura e gênero textual. A leitura é um instrumento de alta possibilidade para compreensão e probabilidade de aprendizagem no processo construído, através do planejamento da oficina com interações de leitura no espaço escolar.

Para Freire (1989) a democracia é alcançada quando o leitor é crítico, partindo do processo de adquirir a linguagem escrita e a prática de leitura, envolvendo desta forma a compreensão do processo de alfabetização através da palavra inserida, debatida e contextualizada, atingindo um diálogo com a leitura do mundo real sendo estimulada pela leitura do aluno para que haja a transformação. As aulas ministradas pelo projeto 
devem ser planejadas quanto ao tempo de duração, verificando as referências bibliográficas a serem usadas, comparando as mais antigas as mais atuais, provocando um comparativo da importância atual e a contribuição da temática, considerando os diversos atores sócias envolvidos no processo de ensino aprendizagem na construção dos saberes. Para Relvas (2012, p.42-44), "a aprendizagem fica melhor quando sofre estímulos as linguagens oral, escrita, cantada, expressão facial e corporal que melhorem as capacidades cognitivas do aluno".

A adequação do texto trabalhado pode fazer toda diferença, o professor precisa ter a sensibilidade de escolher o texto de acordo com a realidade dos jovens, promovendo a vivência do cotidiano deles através da escola com o desenvolvimento do conhecimento. A cultura da leitura pode ser desabrochada com projetos dessa natureza básica que envolve as verdades e interesses universais, promovendo conhecimentos novos e o avanço da ciência. Segundo Rangel (20ro), corrobora que os projetos são opções para acabar com o ensino tradicionalista da gramática normativa, com uma nova postura flexiva e descritiva, propiciando os conhecimentos da língua tratada se abordados sistematicamente na escola os diferentes usos da linguagem de acordo com a necessidade dos contextos experimentados. Os projetos referentes a leitura são pensados para sanar o desenvolvimento do cidadão critico, reflexivo e emocional do estudante.

\section{PROJETOS AMBIENTAIS NO CONTEXTO ESCOLAR}

O panorama mundial aborda a necessidade das mudanças quanto as questões ambientais, e o princípio deve ocorrer em casa, na escola, na cidade até que as práticas inclusivas da sustentabilidade deixem de ser um ato isolado, mas que possa acontecer nas ações coletivas no contexto global.

Especificamente no Brasil Layrargues (2017) defende que o campo ambiental, o país é caracterizado como complexo, pois abrange diversas afiliações e estilos de pensamentos ambientais. Nessa área, estilos de pensamento ambiental sofrem com posições antagônicas e tentam mudar o cenário a favor da hegemonia interpretativa da questão. Contudo, mesmo com a discórdia dos pensamentos sobre as dificuldades 
relatadas, os estilos de pensamento são guiados por uma ética comum para seguir os princípios da defesa do meio ambiente LAYRARGUES, 2017).

As atividades escolares requerem um planejamento anual e semanal para execução das mesmas, contudo as práticas curriculares ocorrem gradativamente e não ocorrem integralmente. A abordagem das temáticas importante como Meio Ambiente, na maioria das vezes precisam ser mais intensas e constantes no cotidiano escolar. $\mathrm{O}$ envolvimento dos educadores irá contemplar ou não a eficácia da inclusão da temática interdisciplinar na proposta do currículo

Os projetos interdisciplinares proporcionam o trabalho coletivo com planejamento prévio, despertando o processo de aprendizagem e conhecimento mútuo dos colegas e do compartilhamento sobre o assunto, construindo pontes para o conhecimento através de atividades na escola ou mesmo em outro espaço. As práticas curriculares devem ser apoiadas pela gestão e coordenação da escola que são incentivadores da continuidade do processo até que seja cumprido positivamente.

$\mathrm{Na}$ revisão de literatura os projetos das Escolas participantes da IV Conferência Nacional Infanto Juvenil sobre Meio Ambiente, na análise dos projetos as políticas públicas valeram, pois em 2003 a ação do ministério da Educação e do Meio Ambiente lançaram a Conferência Nacional Infanto Juvenil sobre Meio Ambiente havendo protagonismo Infanto Juvenil e participação da comunidade na construção coletiva dos projetos, por isso os projetos foram eficazes.

$\mathrm{Na}$ análise de projetos a pesquisa da escola pública do município de Quixadá do ensino fundamental I e II em 2020 resultou da reflexão dos profissionais quanto as dificuldades para executar o projeto sobre Meio Ambiente, mas abriu novos paradigmas para refletir e planejar melhor as ações.

No acervo das pesquisas analisa-se o resultado do no $9^{\underline{0}}$ ano do Ensino Fundamental II até o $3^{\circ}$ ano do Ensino Médio em uma Escola Estadual da Educação Básica em Santo Ângelo - RS, com Projeto de reciclagem, que concluiu um trabalho em equipe significativo na relação aluno/ professor e no efeito da aprendizagem dos jovens. Após as análises de projetos escolares segundo Brentano (2015) a ênfase em um projeto deve ser adequado aos ambientes, não somente vinculados a estética, mas sendo complexo deve haver subsistemas para efetivado simultaneamente. 


\section{ENSINO- APRENDIZAGEM}

Para o alcance da aprendizagem é importante a formação inicial e continuada com ênfase na Educação Ambiental, conforme Uhmann e Vorpagel (2018, p. 6r) pois "faz diferença na constituição de sujeitos críticos em relação à realidade, graças à possibilidade de trocas de vivências entre professores e licenciandos.”. A ideia é fortalecida quanto a formação dos educadores que potencializados pelo estímulo podem mudar com a sensibilização ambiental dos educandos, principalmente se toda comunidade escolar avançar na formação que possibilita transformação social.

A prática de EA desenvolvida frequentemente evidencia o repensar dos alunos e professores através das atitudes humanas cotidianas, surgindo senso crítico, desta forma evidência na observação dos seus efeitos em relação a natureza e sociedade. Contudo percebe-se a importância do papel do professor no contexto escolar e os agentes de diversas instituições públicas e privadas. Estes são capazes de transformar e ativar a sensibilização ambiental.

A preocupação com o meio ambiente deve ser despertada na sala de aula, porque é papel da escolar implementar a cultura para valorização do meio ambiente, dos recursos naturais. Então surge a necessidade de capacitar os professores em relação à temática.

\footnotetext{
A Educação Ambiental é uma dimensão da educação, é atividade intencional da prática social, que deve imprimir ao desenvolvimento individual um caráter social em sua relação com a natureza e com os outros seres humanos, visando potencializar essa atividade humana com a finalidade de torná-la plena de prática social e de ética ambiental. (BRASIL, 2012, p.2).
}

\section{FUNDAMENTAÇÃO TEÓRICA}

A educação ambiente (EA), é a fonte que move o trabalho presente, e as propostas são desveladas na medida que o autor afirma, Cortes Junior e Fernandez (2016) a Educação Ambiental (EA) é o progresso empírico da prática social através das relações construídas respeitosas entre a natureza e o ser humano, obedecendo a ética ambiental. A intenção é viabilizar a informação para todos e que seja funcional e permanente apesar de aprender novas realidades sobre o tema. 
Segundo Barchi (2016, p. 636) “para a destruição ecológica existe uma maneira de promoção do bom convívio entre homens e planeta que é a educação ambiental (E.A.)”. Ela se faz necessária em meio ao caos de poluição e descaso por parte da sociedade, é necessário atingir o todo. "Viabilizar a dimensão apontada nos processos de decisão para estudar o meio ambiente é um dos maiores desafios”. (MANTAÑO; SOUZA. 2016, p. 490). Hofstatter, Oliveira e Soutto (2016), complementa as contribuições dos autores citados, a escola tem como papel principal promover uma formação integral do estudante, por isso faz -se necessário a abordagem da EA com a necessidade de desenvolver o raciocínio crítico - interacionista do indivíduo.

Os projetos que são fontes de esperança para mudanças no processo de aprendizagem, politizam sobre a educação atual, que implica na reconstrução da mesma pelo modelo tão arcaico que por vezes mais estagnados pela falta de planejamento governamental. A importância do ambiente adequado, segundo Relvas (20II, p.27-28)," o ambiente propício para execução de projetos na escola deve preceder de ações teóricas da aprendizagem até chegar até a prática, que engloba a capacidade, a experiência holística (compreensão do assunto global) e útil para o ato de aprender". A eficácia do ensino e aprendizagem só é possível se houver um bom planejamento e a mediação do saber através de debates na construção através de projetos que se revela tão atrativo nos trabalhos acadêmicos.

\section{PROCEDIMENTOS METODOLÓGICOS}

A pesquisa realizada parte de materiais já publicados que fornecem propostos para o avanço e melhoria do ensino com projetos no meio escolar. Para Galvão e Pereira (2014, p. 183) "revisões sistemáticas de boa qualidade são consideradas o melhor nível de evidência para tomada de decisão".

O instrumento escolhido se baseou por meio de observações diretas no decorrer da prática docente. A abordagem é qualitativa, o meio ambiente, os livros, fornecem dados para coleta, com a leitura dos fenômenos com integrantes da situação. Segundo (CHARMAZ, 2009) a abordagem qualitativa atende necessidades que surgem durante a investigação, já que a pesquisa qualitativa é flexível. 
A análise de projetos foi verificada em três resultados de trabalhos científicos de lugares diferentes no Brasil : CE,SC e DF durante a revisão bibliográfica.

Conforme Gil (2010), um problema é relevante em termos científicos à medida que conduz à novos conhecimentos. Nesse caminho, esta pesquisa se classifica como qualitativa, pois há a preocupação em entender os significados e a compreensão da realidade dos objetos aqui analisados. Quanto ao nível em que se encontra, esta é uma pesquisa exploratória (GIL, 2010).

O método científico é de natureza hipotética dedutivo expressando a dificuldade do problema, podendo deduzir consequências em fase de teste. A metodologia tem um itinerário de revisão sistematizado pela literatura, na qual foi referenciada por busca em sites de teses, dissertações, bem como publicação em revistas, jornais. Como afirma Mancini e Sampaio (2007), apontando que as revisões de literatura são caracterizadas pela análise da informação de estudos mais relevantes publicados sobre um tema, resumindo o conhecimento para conclusão sobre o assunto.

O projeto abordado trata das oficinas de leitura relacionada ao tema proposto, uma vez que a dificuldade de escrita e leitura está presente nas escolas. Nesse sentido, Lajolo (2005), fala sobre o gosto pela leitura é uma tarefa iniciada na escola, com estudos dirigidos através dos diversos gêneros textuais para valorização da leitura. Os gêneros textuais podem ser orais e escritos, bem como as variações estilísticas e as possibilidades de dialogar com os escritos e paulatinamente os leitores aprendem conforme as particularidades da literatura.

Rodrigues (2015), as estratégias metodológicas aplicadas com a preparação prévia da programação entre discussões e leituras para que os participantes possam se familiarizar com as atividades para estímulos gerando reflexões, bem como o trabalho para o despertar da criatividade, através das percepções dos aspectos éticos, estéticos e políticos da exposição entre a natureza e a sociedade praticando a crítica e autocrítica.

\section{CONSIDERAÇÕES FINAIS}

O relato final é para que as propostas no ambiente escolar propagem resultados eficientes, uma vez que a educação desde seu início se depara com situações problemas que são desencadeadas com o preparo do aluno para as diversidades do 
planeta, constituindo um bom entendimento do seu papel na sociedade e harmonizando sua colaboração quanto ao meio no qual está inserido.

A ação de intervenção depende do processo das práticas pedagógicas no processo educacional gerando ações interventivas, já que os discentes instigam a educação na escola ou mesmo fora dela. Do ensino infantil até o ensino médio, os parâmetros curriculares devem atender os privilégios, sem esquecer da metodologia a ser aplicada endossando a prática pedagógica através de projetos para vida científico social do aluno.

Lembrando que não há práticas educacionais infalíveis se não houver estímulo para que aconteça o bom resultado. Diante da amostra de revisão é possível aplicar esses projetos bem como executa -os com toda dedicação acreditando no resultado promissor.

Os projetos sobre Meio Ambiente devem continuar, obecendo tempo e espaço, contudo devem ser pautados na coletividade, persistência, sendo prioridade até haver execução e resultados do ensino aprendizagem do aluno, desta maneira não deixando de ser discutido continuamente até o cidadão aprender e ser crítico quanto a temática, infalivelmente exercer o papel de professor em relação ao propósito.

\section{REFERÊNCIAS}

BARBA, M.D. 'Déficit de natureza' provoca problemas físicos e mentais em crianças, alerta especialista, BBC Brasil, São Paulo, 25, jun. 2016.

BARCHI, R. Educação ambiental e (eco)governamentalidade. Revista Ciência \& Educação (Bauru), v.22, n.3, Bauru - SP, p. 635-650, 2016. Disponível em: $\langle$ http://www.scielo.br/pdf/ciedu/v22n3/1516-7313-ciedu-22-03-0635.pdf 〉. Acesso em: 23, jan. 2019 .

BRASIL. V Conferência Infantojuvenil pelo Meio Ambiente. [2017]. Disponível em: 〈http://conferenciainfanto.mec.gov.br $〉$. Acesso em: 28 de set. 202I.

BRASIL. Ministério da Educação. Conselho Nacional de Educação (CNE). Parecer $\mathrm{CNE} / \mathrm{CP}$ no 14 , de 6 de junho de 2012. Institui as Diretrizes Curriculares para a Educação Ambiental. Diário Oficial da União, Brasília, DF, 15. jun. 2012. 
BRENTANO, T. A proteção Contra Incêndios no Projeto de Edificações. 3. ed. Porto Alegre: Edição do Autor, 2015.

CHARMAZ, Kathy. A Construção da Teoria Fundamentada: guia prático para análise qualitativa. Porto Alegre: Artmed; 2009, p. 28-40.

CORTES JUNIOR, L. P.; FERNANDEZ, C. A EDUCAÇÃO AMBIENTAL NA FORMAÇÃO DE PROFESSORES DE QUÍMICA: ESTUDO DIAGNÓSTICO E REPRESENTAÇÕES SOCIAIS. Revista Química Nova, v.39, n.6, São Paulo - SP, p.748-756, 2016. Disponível em: 〈http://www.scielo.br/pdf/qn/v39n6/oroo-4042-qn39-06-0748.pdf $>$. Acesso em: 23, jan. 2019.

FREIRE, P. A importância do Ato de Ler: três artigos que se completam. São Paulo: Cortez, 1989. P.44-48.

GALVÃO, Taís Feire; PEREIRA, Maurício Gomes. Revisões sistemáticas da literatura: passos para sua elaboração. Revista Epidemiologia e Serviços de Saúde, 23(I): 183-184. DF 2014 .

GIL, A. C. Métodos e técnicas de pesquisa social. 6. ed. São Paulo: Atlas, 2010.

HOFSTATTER, L. J. V.; OLIVEIRA, H. T.; SOUTO, F. J. B. Uma contribuição da educação ambiental crítica para (des)construção do olhar sobre a seca no semiárido baiano. Revista Ciência \& Educação (Bauru), v.22, n.3, Bauru - SP, p.615-633, 2016. Disponível em: <http://www.scielo.br/pdf/ciedu/v22n3/1516-7313-ciedu-22-03o615.pdf $>$. Acesso em: 23, jan. 2019

LAJOLO. M. Do mundo da leitura para a leitura do mundo. São Paulo: Ática, 2005.p. $20-26$.

LAYRARGUES, P. P. Anti-ecologismo no Brasil: reflexões ecopolíticas sobre o modelo do desenvolvimentismo-extrativista-predatório e a desregulação ambiental pública. In: OLIVEIRA, M.M.D., MENDES, M., HANSEL, C. M., DAMIANI, S. (Orgs.). Cidadania, meio ambiente e sustentabilidade. Caxias do Sul: EDUCS. p. 325356. 2017. 
MANCINI, MC; SAMPAIO, RF. Estudos de revisão sistemática: um guia para síntese criteriosa da evidência científica. Rev. bras. fisioter, São Carlos, v. II, n. I, p. 83-89, fev. 2007 .

MONTAÑO, R.; SOUZA, M. P. Integração entre planejamento do uso do solo e de recursos hídricos: a disponibilidade hídrica como critério para a localização de empreendimentos. Revista Engenharia Sanitária e Ambiental, v.21 n.3, Rio de Janeiro - RJ, p.489-495, 2016. Disponível em: < http://www.scielo.br/pdf/esa/v2In3/ı8o94457-esa-Si413_41522016118729.pdf >. Acesso em: 23, jan. 2019.

PINHEIRO, Alexsandra Alves de Sousa; OLIVEIRA NETO, Benjamin Machado de; MACIEL, Nara Maria Tavares Câmara; A importância da educação ambiental para o aprimoramento profissional, docente e humano. Ensino em Perspectivas, Fortaleza, v. 2, n. I, 2021

RELVAS, M.P. Neurociência na prática pedagógica. Rio de Janeiro: Wak, 2012. p.4244 .

RELVAS, M.P. Neurociências e transtornos de aprendizagem: as múltiplas eficiências para uma educação inclusiva. Rio de Janeiro: Wak, 20Ir. p.27-28.

RODRIGUES, C. (2015). O vagabonding como estratégia pedagógica para a "desconstrução fenomenológica" em programas experienciais de educação ambiental. Educação em Revista, 3I(I): 303-227

ROSS, A.; BECKER, E. L. S. Educação Ambiental e Sustentabilidade. Revista Eletrônica em Gestão, Educação e Tecnologia Ambiental, Santa Maria- RS, v.5, n.5, p.857-866, 2012. Disponível em: 〈https://periodicos.ufsm.br/reget/article/viewFile/4259/3035>. Acesso em: 22, jan. 2019.

SANTANNA, Geraldo José. Planejamento, gestão e legislação escolar. I⿳亠口冋 Ed. São Paulo: Érica, 2014. P. 55-59.

UHMANN, R. I. M.; VORPAGEL, F. S. Educação Ambiental em Foco no Ensino Básico. Pesquisa em Educação Ambiental , v. 13, p. 53-68, 2018. Disponível em: 
http://www.periodicos.rc.biblioteca.unesp.br/index.php/pesquisa/article/view/r298 9 .

Acesso em: 28 set. 202I.

VASCONCELLOS, C. dos S. Planejamento: Projeto de Ensino-Aprendizagem e Projeto Político Pedagógico - elementos metodológicos para elaboração e realização. 24 ed. São Paulo: Libertad, 2014.

YIN, Roberto K. Estudo de caso: planejamento e métodos. 4. ed. Porto Alegre: Bookman, 20I0. 